Factors associated with poly drug use in adolescents

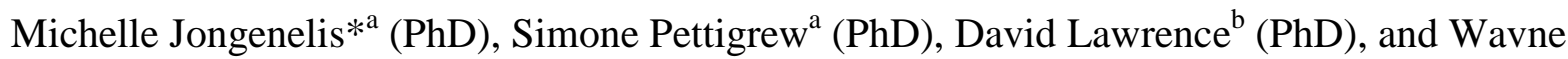
Rikkers $^{\mathrm{b}}$ (BA)

${ }^{*}$ Corresponding author

${ }^{\mathrm{a}}$ School of Psychology

Curtin University

Kent St, Bentley, 6102

Perth, Western Australia, Australia

Ph: +61 892665797

Michelle.jongenelis@curtin.edu.au

Simone.pettigrew@curtin.edu.au

${ }^{\mathrm{b}}$ Graduate School of Education

The University of Western Australia

35 Stirling Highway, Crawley, 6009

Perth, Western Australia, Australia

David.Lawrence@uwa.edu.au

Wavne.rikkers@uwa.edu.au

Running head: Poly drug use in adolescents 


\begin{abstract}
Poly drug use in adolescents represents a significant public health issue, heightening risk for abuse, dependency, and a variety of short- and long-term psychological, psychosocial, and health consequences. However, past studies have typically examined just one or two substances in isolation and there is a lack of research that has comprehensively examined possible predictors of poly drug use in adolescents. To inform the development of comprehensive prevention programs that can simultaneously target multiple substances, the present study sought to identify psychological, environmental, and demographic factors that are most strongly associated with alcohol, tobacco, and cannabis poly drug use. Adolescents aged 15 to 17 years ( $n=1661 ; 50.9 \%$ male) completed a survey on their use of alcohol, tobacco, and cannabis over the last 30 days. Various psychological, environmental, and demographic factors were also assessed. Weighted multiple-level logistic regression was conducted to assess the factors associated with poly drug use. In total, $20.3 \%$ of respondents had used at least one substance, 6.7\% reported using two substances, and 3.3\% reported using all three substances. The most common combined pattern of use was alcohol and tobacco, followed by alcohol and cannabis. Several factors emerged as significant, with conduct problems, depression, and the school environment accounting for the most variance. Specific psychological and environmental factors appear to be particularly important domains to target in adolescent substance use prevention programs. Early identification of adolescent depression and conduct problems and the development of programs that address these symptoms in youth may be effective approaches to delaying or preventing poly drug use in this population.
\end{abstract}

Keywords: poly drug use; alcohol; tobacco; cannabis; adolescents; prevention 


\section{Factors associated with poly drug use in adolescents}

Adolescence is a key period for exposure to and experimentation with a range of harmful substances (Marshall, 2014; Spear, 2000). The three substances that have received most research attention to date in this population are alcohol, tobacco, and cannabis, which are the most commonly used drugs among adolescents (Johnston, O’Malley, Miech, Bachman, \& Schulenberg, 2015; White \& Williams, 2016). While all three substances have high rates of associated physical and psychological short- and long-term harms in the general population, negative outcomes are exacerbated among adolescents. For example, consumption of alcohol, tobacco, and cannabis in adolescence can permanently affect the structure and function of the adolescent's brain, resulting in long term difficulties with behavioural regulation and executive functioning (Ashtari et al., 2011; Dwyer, McQuown, \& Leslie, 2009; Ewing, Sakhardande, \& Blakemore, 2014; Jacobus, Bava, Cohen-Zion, Mahmood, \& Tapert, 2009; Lisdahl, Gilbart, Wright, \& Shollenbarger, 2013; Wilson et al., 2000).

Reflecting the high social and economic costs associated with alcohol, tobacco, and cannabis use, there is a substantial body of work investigating factors associated with the consumption of these products (recent reviews and meta-analyses include Cooke, Dahdah, Norman, \& French, 2016; Grigsby, Forster, Unger, \& Sussman, 2016; Marshall, 2014; Peters, Budney, \& Carroll, 2012). Of interest to the present study is poly drug use, which occurs in a substantial minority of youth (Busch, Van Stel, Schrijvers, \& de Leeuw, 2013; Leatherdale \& Ahmed, 2010; Marshall, 2014). In Australia, the context of the present study, a recent longitudinal study of tobacco, alcohol, and cannabis use in over 2000 14- to 15-year-olds revealed poly drug use in 6.5\% of the sample (Kelly, Evans-Whipp, et al., 2015). This was deemed a "small but notable proportion" by the authors (p.632). 
Poly drug use by adolescents has been linked with school non-completion, low academic achievement, psychosocial problems, depressive symptoms, psychological distress, legal problems, interpersonal difficulties, risky sexual practices, and physical health issues (Bohnert et al., 2014; Connell, Gilreath, \& Hansen, 2009; Fallu, Brière, \& Janosz, 2014; Felton, Kofler, Lopez, Saunders, \& Kilpatrick, 2015; Kelly, Chan, Mason, \& Williams, 2015; Kelly, Evans-Whipp, et al., 2015; Peters et al., 2012). Poly drug use among adolescents thus represents a significant public health issue, resulting in calls for a more comprehensive and integrated approach to youth prevention programs (Camenga, Klein, \& Roy, 2006; Hale, Fitzgerald-Yau, \& Viner, 2014; Leatherdale, Hammond, \& Ahmed, 2008; Wiefferink et al., 2006). The development of integrated interventions requires the identification of common factors demonstrating meaningful effect sizes across all three substances to facilitate selection of the most relevant modifiable factors to address in intervention design. A recent systematic review of 26 latent class analysis studies identified higher age, peer and parental substance use, and poor academic achievement as factors consistently linked to poly drug use among adolescents (Tomczyk, Isensee, \& Hanewinkel, 2016). However, the majority of included studies explored a restricted range of predictors, potentially overstating the importance of these predictors in the analyses conducted. Furthermore, factors such as self-esteem and social connectedness, which have been linked to the use of individual substances (Bond et al., 2007; Scheier, Botvin, Griffin, \& Diaz, 2000; Shortt, Hutchinson, Chapman, \& Toumbourou, 2007; Veselska et al., 2009), do not appear to have been assessed in the context of poly drug use.

\section{Present Study}

Assessing the relative contribution of the large number of potential factors associated with poly drug use among adolescents is important for determining where intervention efforts 
should be directed to maximize their effectiveness. Accordingly, the present study aimed to identify psychological, environmental, and demographic factors that are most strongly associated with poly drug use in a nationally representative sample of adolescents. Of specific interest was the identification of common factors demonstrating meaningful effect sizes for the consumption of alcohol, tobacco, and cannabis individually and in combination to inform the development of integrated interventions that target multiple risk factors simultaneously.

\section{Method}

\section{Design and Sample}

This study utilized data captured by the Young Minds Matter national household survey conducted May 2013 to April 2014 by the Telethon Kids Institute on behalf of the Australian Government Department of Health (see detailed information pertaining to the survey methodology in J. Hafekost et al., 2016). In this cross-sectional, population-based study, data from 6,310 children aged 4-17 years residing in randomly selected households across Australia were collected via interviews with caregivers (household response rate: 55\%). In addition to these interviews with caregivers, children aged 11 to 17 years were invited to complete a youth self-report questionnaire. Data were obtained from 2,967 children, representing $89 \%$ of eligible adolescents in the selected households. The survey sample was selected via multi-stage area based sampling, with Statistical Area 1 (SA1) areas selected at the first stage, and then families selected within the selected SA1 areas (see Telethon Kids Institute (2015) for a detailed explanation of the recruitment process).

Data from respondents aged 15 to 17 years $(n=1661)$ were extracted from the results of the larger study. This sub-group was selected due to 15 being a particularly important age for the commencement of substance use (Matuszka et al., 2017), as reflected in prevalence rates from the Australian Secondary Students Alcohol and Drug Survey where past month 
use of alcohol, cigarettes, and cannabis was substantially greater in 15 to 17 year olds compared to 12 to 14 year olds (alcohol: 12\% cf. 41\%; cigarettes: 3\% cf. 13\%; cannabis: 3\% cf. 11\%) (White \& Williams, 2016).

The sample profile for the present study is presented in Table 1. The sample was weighted by sex, age, family size, and household income to ensure comparability to the population of 11 to 17 year olds in Australia (as per Australian Bureau of Statistics, 2014). This weighting also took into account patterns of non-response (see Telethon Kids Institute (2015) for a detailed explanation of the weighting process).

Insert Table 1 about here

\section{Measures}

Dependent variables. The dependent variables under investigation were alcohol use, tobacco use, cannabis use, and poly drug use. As per the items included in the Young Minds Matter survey, use of alcohol, tobacco, and cannabis was defined as any consumption in the last 30 days (categorized dichotomously: $0=$ no, $1=$ yes). Poly drug use was treated as a multiple-level variable and categorized as follows: 0 = no drug use, $1=$ use of one substance, 2 = use of any two substances, 3 = use of all three substances (as per Reyes, Perez, Colón, Dowell, \& Cumsille, 2013). Respondents were also asked about their use of other drugs such as ecstasy, meth/amphetamines, cocaine, hallucinogens, inhalants, heroin, and steroids, and their use of prescription drugs for non-medical purposes. Only 40 respondents reported use of any of these drugs in the last 30 days, precluding analysis of factors associated with use due to insufficient sample size.

\section{Independent variables.}


Psychological factors. The assessed psychological factors in the present study were emotional symptoms, conduct problems, peer problems, hyperactivity, self-esteem, and depression. Emotional symptoms (e.g., I am often unhappy, downhearted or tearful), conduct problems (e.g., I fight a lot), peer problems (e.g., I am usually on my own), and hyperactivity (e.g., I am constantly fidgeting or squirming) were each measured using their respective 5item subscales of the Strengths and Difficulties Questionnaire (SDQ; Goodman, 1994). The SDQ is a widely used and valid measure of psychological difficulties in children (Goodman, 2001). Cronbach’s alphas for each were $.74, .60, .61$, and .73 respectively. Self-esteem was measured using the 12-item Adolescent Self-Esteem Questionnaire (ASQ), a scale developed by the survey team. The ASQ has been found to be a valid and reliable measure of selfesteem, with high internal consistency, construct validity, and test-retest reliability (K. Hafekost, Boterhoven de Haan, Lawrence, Sawyer, \& Zubrick, 2017). Cronbach’s alpha of the ASQ in the present study was .86. Whether respondents met criteria for a diagnosis of major depressive disorder was determined by their responses to the DISC-IV Youth Informant Major Depressive Disorder Module (developed by the National Institute of Mental Health; Shaffer, Fisher, Lucas, Dulcan, \& Schwab-Stone, 2000). The DISC-IV applies criteria as specified in the Diagnostic and Statistical Manual for Mental Disorders Version IV (DSM-IV) to establish nature and duration of symptoms and impact on functioning to determine diagnostic status.

Environmental factors. The environmental factors examined in the present study fell into three categories: social, school, and parental. Environmental social factors were assessed using items developed by the study team and included respondents' number of friends (single item: About how many friends do you have who you either hang out with, talk to on the phone, regularly send messages to either through text or online, or get together with socially?; $0=0$ friends to $9=20$ friends or more) and degree of social connectedness (single 
item: How well do you get along with people?; 1 = very well to $4=$ not well at all).

Environmental school factors included feelings towards school (single item developed by the study team: How do you feel about going to school?; 1 = I like school very much to 5 = I hate school), school connectedness (measured using the School Connectedness Scale from the National Longitudinal Study of Adolescent to Adult Health; Harris \& Udry, 1994-2008; Cronbach’s alpha in the present study $=.84$ ), school engagement (measured using a scale developed by the survey team and based on items drawn from the School Life Instrument; Ainley \& Bourke, 1992; Cronbach’s alpha in the present study = .99), and self-reported frequency of being bullied (single item developed by the study team: In the last 12 months, how often were you bullied or cyber bullied? 1 = I was not bullied in the last 12 months to 6 = I was bullied most days). Finally, the assessed parental factor included degree of parental monitoring (composite of How much do your parents know about what you are doing? and How much do your parents know about how you are feeling?; 1 = a lot to 4 = not at all; Cronbach’s alpha $=.76)$.

Demographic factors. The demographic variables explored in the present study were gender, age, socioeconomic status (SES), and country of birth. Information pertaining to respondents' SES (calculated using the Australian Bureau of Statistics’ Index of Relative Socio-economic Disadvantage of the SA1 where the family was living at the time of the survey: Australian Bureau of Statistics (ABS), 2011) and country of birth was gathered from a survey completed by the respondents' parents or carers and merged with the youth selfreport data. SES deciles (where 1 represents the most disadvantaged area and 10 the least disadvantaged) were used in analyses. Country of birth was treated as a dichotomous variable (1 = Australia, 2 = overseas).

\section{Statistical Analysis}


As noted above, drug use was treated as a multiple-level variable. As such, multinomial logistic regression analyses were used to assess the factors associated with poly drug use. Binary logistic regression analyses were conducted to assess the factors associated with alcohol, tobacco, and cannabis use. These analyses were conducted in MPlus utilizing the weighted sample. The Maximum Likelihood Robust estimator was used to estimate parameters and calculate odds ratios. As the recruitment process involved sampling families within selected areas, and families living within the same small geographic area may share some similarities, the clustered nature of the sample design was accounted for using the TYPE = COMPLEX command in MPlus. All independent variables were treated as observed (either continuous or categorical) variables in the assessed models. For the DISC-IV Youth Informant Major Depressive Disorder Module, responses were used to determine whether participants met criteria for Major Depressive Disorder (coded 0) or did not meet criteria (coded 1), and this dichotomous variable was used in analyses. For all other multiple-item scales, grand mean scores were used.

\section{Results}

\section{Poly Drug Use}

Prevalence of alcohol, tobacco, and cannabis use in the sample is reported in Table 1. In the last 30 days, $27 \%$ of respondents reported consuming alcohol, $10 \%$ of respondents reported using tobacco, and 7\% reported using cannabis. One-fifth (20\%) of respondents reported using one substance, 7\% reported using two substances, and 3\% reported using all three substances. Table 2 presents prevalence of substance use stratified by alcohol, tobacco, and cannabis user status. A majority of tobacco users and cannabis users were also alcohol users, while a minority of alcohol users were also tobacco or cannabis users. 
Insert Table 2 about here

Full results from the logistic regression assessing factors associated with poly drug use are presented in Table 3 and a visual depiction of the significant findings is presented in Figure 1 . The entered factors accounted for $31 \%$ of the variance in poly drug use. For the demographic factors, age and country of birth emerged as significant. The odds of engaging in poly drug use significantly increased as age increased, while the odds of engaging in poly drug use were significantly lower for those born overseas. For the psychological factors, those reporting conduct problems and major depressive disorder had greater odds of engaging in poly drug use, while odds of engaging in poly drug use were lower among those with peer problems and emotional problems. For the environmental factors, the odds of engaging in poly drug use were greater among those who reported having a larger number of friends and a greater degree of social connectedness. The odds of engaging in poly drug use were also greater among those with lower levels of school engagement and those who disliked school.

\section{Insert Table 3 about here}

Insert Figure 1 about here

\section{Alcohol, Tobacco, and Cannabis Use}

Alcohol, tobacco, and cannabis use were explored independently but in the same model to identify any shared factors that could become the targets of a comprehensive substance use prevention program. Full results from this logistic regression are presented in Table 4 and a visual depiction of the significant findings is presented in Figure 2. The entered factors accounted for $29 \%$ of the variance in alcohol use, $32 \%$ of the variance in tobacco use, 
and $30 \%$ of the variance in cannabis use. Most of the factors included in the model were found to be significant, with the exception of gender, SES, and being a victim of bullying.

An examination of common risk factors revealed that higher conduct problem scores were associated with greater odds of using each of the three substances under investigation. Alcohol and tobacco appeared to share many common factors, with odds of use of each of these two substances found to be greater among those with major depressive disorder and those reporting more friends, and lower among those reporting emotional problems.

When each of the three substances was examined individually to identify additional relevant factors, the odds of using alcohol were greater in those who were older, born in Australia, more socially connected, disliked school, and were less engaged in school. The odds of using alcohol were lower among those with higher self-esteem and peer problems. For tobacco, usage odds were greater among those reporting greater hyperactivity and lower school connectedness. For cannabis, the odds of use were greater among those reporting reduced parental monitoring.

Insert Table 4 about here

Insert Figure 2 about here

\section{Discussion}

Poly drug use has been linked with a variety of medical, psychological, and psychosocial harms among adolescents (Bohnert et al., 2014; Fallu et al., 2014; Felton et al., 2015; Kelly, Chan, et al., 2015; Kelly, Evans-Whipp, et al., 2015; Peters et al., 2012). The severity of these harms highlights the importance of identifying the factors that contribute to the consumption of multiple substances to inform future prevention programs (Hublet et al., 
2015; Marshall, 2014). The primary focus in the literature to date on factors associated with the use of individual substances has resulted in a paucity of information to guide the development of integrated interventions designed to address poly drug use. To identify factors that can be the focus of comprehensive interventions, the present study investigated the psychological, environmental, and demographic factors associated with poly drug use, with a particular focus on common factors demonstrating meaningful effect sizes for the consumption of alcohol, tobacco, and cannabis individually and in combination.

Of the psychological factors under investigation, conduct problems was the most influential. This factor was significantly associated with poly drug use and use of each of the three investigated substances individually. Adolescents with behavioral problems such as aggression and rule-breaking may thus be especially at risk of substance use and as such could be a primary target of prevention efforts. While the cross-sectional nature of the study means that causation cannot be established, these findings are consistent with previous longitudinal research that has found conduct problems to be prospectively associated with substance use (e.g., King, Iacono, \& McGue, 2004; Maslowsky \& Schulenberg, 2013). However, this past work examined each substance in isolation, and the present study extends these previous findings by providing evidence that conduct problems are associated with poly drug use as well as the use of individual substances.

Diagnosis of major depressive disorder was found to be significantly associated with poly drug use and with alcohol use and tobacco use individually. Recent studies and reviews have documented the use of alcohol and tobacco by adolescents as self-medication to cope with and/or alleviate psychological difficulties, particularly the emotional experiences associated with depressive disorders (Grigsby et al., 2016; Stapinski et al., 2016). Early identification of adolescent depression and the development of programs that address 
depressive symptomatology in youth may be effective approaches to delaying or preventing poly drug use in this population.

Of the environmental factors included in the study, the school environment was found to be especially important. Supporting previous findings of an inverse relationship between adolescent substance use and school engagement/connectedness (Bond et al., 2007; Li et al., 2011), poorer school engagement and more negative feelings towards school were associated with poly drug use and alcohol use, and poorer school connectedness was associated with tobacco use. These results suggest that the school environment plays an important role in protecting against youth substance use and that effective targeting of intervention programs may be aided by the identification of adolescents showing signs of disengagement.

\section{Implications}

The present study identified multiple factors associated with poly drug use that could become the focus of programs that aim to reduce substance use in adolescents. The most influential factors, after taking into account sociodemographic variables, were conduct problems, depressive symptoms, and the school environment. Universal interventions that address the complexity of issues faced by youth and are designed to account for common comorbidities such as those identified in this study may be more effective than interventions that are focussed primarily on substance use and are therefore designed to target just one issue of many. In support of this assertion, a systematic review of the effectiveness of schoolbased universal programs for the prevention of alcohol misuse in youth found that generic prevention programs were more effective at reducing alcohol use compared to alcoholspecific prevention programs (Foxcroft \& Tsertsvadze, 2012). School-based interventions based on psychosocial and developmental approaches that focus on the enhancement of protective factors within the adolescent's environment (e.g., developing support networks) 
and at the individual level (e.g., developing personal skills such as problem solving, selfregulation of emotions such as anger, and dealing with conflict) may therefore serve to address the multitude of factors faced by adolescents, thereby both directly and indirectly targeting substance use behaviors.

\section{Limitations}

The results of the present study need to be interpreted in the context of the methodological limitations. First, as noted, the study was cross-sectional in nature and causation cannot be determined. It is likely that reciprocal relationships and interactions are present between the variables that warrant further investigation. Second, as a result of the differing methods used to assess alcohol, tobacco, and cannabis use in the Young Minds Matter survey, past 30 day use was the only measure available for all three substances. As any use of these three substances is contraindicated in this age group, the findings provide important insights into the factors that may be most appropriate for inclusion in prevention programs. However, research assessing the factors associated with frequency of use may provide additional useful information that differentiates at-risk youth. Finally, the results pertain to the Australian context. Replication in other countries is needed to ensure prevention programs are tailored to the specific population being targeted.

The present study had several notable strengths. First, the sample size was sufficiently large to provide adequate power for the complex analyses conducted. Second, the recruitment method and weighting of the data increased the chances that the results are representative of Australian adolescents. Finally, in examining the factors associated with poly drug use, the present study provided results with clear implications for potential prevention approaches. This is especially important given the need for evidence-based interventions that efficiently 
and effectively target multiple risk factors and substances (Griffin \& Botvin, 2010; Leatherdale \& Ahmed, 2010).

In conclusion, replacing multiple prevention programs that each target one risk behavior with comprehensive programs that target multiple behaviors and risk factors is likely to be a most cost-effective approach to preventing substance use among adolescents. The present study identified multiple factors associated with poly drug use that could become the focus of such programs. Conduct problems, depressive symptoms, and the school environment appear to be particularly important domains to target to reduce the likelihood of adolescents using alcohol, tobacco, and cannabis individually and in combination. 


\section{Compliance with Ethical Standards}

Funding: Young Minds Matter: the second Australian Child and Adolescent Survey of Mental Health and Wellbeing was funded by the Australian Government Department of Health. No specific funding was received for this analysis.

Disclosure of potential conflicts of interest: The authors declare that they have no conflict of interest

Ethical approval: All procedures performed in studies involving human participants were in accordance with the ethical standards of the institutional and/or national research committee and with the 1964 Helsinki declaration and its later amendments or comparable ethical standards

Statement on the welfare of animals: This article does not contain any studies with animals performed by any of the authors.

Informed consent: Informed consent was obtained from all individual participants included in the study 


\section{References}

Ainley, J., \& Bourke, S. (1992). Student views of primary schooling. Research Papers in Education, 87(2), 107-128.

Ashtari, M., Avants, B., Cyckowski, L., Cervellione, K. L., Roofeh, D., Cook, P., . . Kumra, S. (2011). Medial temporal structures and memory functions in adolescents with heavy cannabis use. Journal of Psychiatric Research, 45(8), 1055-1066.

Australian Bureau of Statistics. (2011). SEIFA Census of Population and Housing: SocioEconomic Indexes for Areas (SEIFA), Australia, 2011. (Cat. no. 2033.0.55.001). Canberra: ABS.

Bohnert, K. M., Walton, M. A., Resko, S., Barry, K. T., Chermack, S. T., Zucker, R. A., . . . Blow, F. C. (2014). Latent class analysis of substance use among adolescents presenting to urban primary care clinics. The American Journal of Drug and Alcohol abuse, 40(1), 44-50.

Bond, L., Butler, H., Thomas, L., Carlin, J., Glover, S., Bowes, G., \& Patton, G. (2007). Social and school connectedness in early secondary school as predictors of late teenage substance use, mental health, and academic outcomes. Journal of Adolescent Health, 40(4), 357.e359-357.e318.

Busch, V., Van Stel, H. F., Schrijvers, A. J., \& de Leeuw, J. R. (2013). Clustering of healthrelated behaviors, health outcomes and demographics in Dutch adolescents: A crosssectional study. BMC Public Health, 13(1), 1118-1128.

Camenga, D. R., Klein, J. D., \& Roy, J. (2006). The changing risk profile of the American adolescent smoker: Implications for prevention programs and tobacco interventions. Journal of Adolescent Health, 39(1), 120.e121-120.e110. 
Connell, C. M., Gilreath, T. D., \& Hansen, N. B. (2009). A multiprocess latent class analysis of the co-occurrence of substance use and sexual risk behavior among adolescents. Journal of Studies on Alcohol and Drugs, 70(6), 943-951.

Cooke, R., Dahdah, M., Norman, P., \& French, D. P. (2016). How well does the theory of planned behaviour predict alcohol consumption? A systematic review and metaanalysis. Health Psychology Review, 10(2), 148-167.

Dwyer, J. B., McQuown, S. C., \& Leslie, F. M. (2009). The dynamic effects of nicotine on the developing brain. Pharmacology \& Therapeutics, 122(2), 125-139.

Ewing, S. W. F., Sakhardande, A., \& Blakemore, S. J. (2014). The effect of alcohol consumption on the adolescent brain: A systematic review of MRI and fMRI studies of alcohol-using youth. NeuroImage: Clinical, 5, 420-437.

Fallu, J. S., Brière, F. N., \& Janosz, M. (2014). Latent classes of substance use in adolescent cannabis users: predictors and subsequent substance-related harm. Frontiers in Psychology, 5. doi:10.3389/fpsyt.2014.00009

Felton, J. W., Kofler, M. J., Lopez, C. M., Saunders, B. E., \& Kilpatrick, D. G. (2015). The emergence of co-occurring adolescent polysubstance use and depressive symptoms: A latent growth modeling approach. Development and Psychopathology, 27, 1367-1383.

Foxcroft, D. R., \& Tsertsvadze, A. (2012). Cochrane Review: Universal school-based prevention programs for alcohol misuse in young people. Evidence-Based Child Health: A Cochrane Review Journal, 7(2), 450-575.

Goodman, R. (1994). A modified version of the Rutter parent questionnaire including extra items on children's strengths: A research note. Journal of Child Psychology and Psychiatry, 35, 1483-1494. 
Goodman, R. (2001). Psychometric properties of the strengths and difficulties questionnaire. Journal of the American Academy of Child \& Adolescent Psychiatry, 40(11), 13371345.

Griffin, K. W., \& Botvin, G. J. (2010). Evidence-based interventions for preventing substance use disorders in adolescents. Child and Adolescent Psychiatric Clinics of North America, 19(3), 505-526.

Grigsby, T. J., Forster, M., Unger, J. B., \& Sussman, S. (2016). Predictors of alcohol-related negative consequences in adolescents: A systematic review of the literature and implications for future research. Journal of Adolescence, 48, 18-35.

Hafekost, J., Lawrence, D., Boterhoven de Haan, K., Johnson, S. E., Saw, S., Buckingham, W. J., . . Zubrick, S. R. (2016). Methodology of Young Minds Matter: The second Australian Child and Adolescent Survey of Mental Health and Wellbeing. Australian \& New Zealand Journal of Psychiatry, 50(9), 866-875.

Hafekost, K., Boterhoven de Haan, K., Lawrence, D., Sawyer, M. G., \& Zubrick, S. R. (2017). Validation of the Adolescent Self-Esteem Questionnaire: Technical report. Telethon Kids Institute and the Graduate School of Education, The University of Western Australia, Perth, Australia.

Hale, D. R., Fitzgerald-Yau, N., \& Viner, R. M. (2014). A systematic review of effective interventions for reducing multiple health risk behaviors in adolescence. American Journal of Public Health, 104(5), e19-e41.

Harris, K. M., \& Udry, J. R. (1994-2008). National Longitudinal Study of Adolescent Health (Add Health), 1994-2008; Wave 1 Public Use Data, Data collection instrument and users guide. Retrieved from https://statacumen.com/teach/ADA1/PDS_data/AddHealthW1_CodeBook.pdf 
Hennessy, E. A., Tanner-Smith, E. E., \& Steinka-Fry, K. T. (2015). Do brief alcohol interventions reduce tobacco use among adolescents and young adults? A systematic review and meta-analysis. Journal of Behavioral Medicine, 38(6), 899-911.

Hublet, A., Bendtsen, P., de Looze, M. E., Fotiou, A., Donnelly, P., Vilhjalmsson, R., . . Ter Bogt, T. F. (2015). Trends in the co-occurrence of tobacco and cannabis use in 15year-olds from 2002 to 2010 in 28 countries of Europe and North America. The European Journal of Public Health, 25(Supplement 2), 73-75.

Jacobus, J., Bava, S., Cohen-Zion, M., Mahmood, O., \& Tapert, S. F. (2009). Functional consequences of marijuana use in adolescents. Pharmacology Biochemistry and Behavior, 92(4), 559-565.

Johnston, L. D., O’Malley, P. M., Miech, R. A., Bachman, J. G., \& Schulenberg, J. E. (2015). Monitoring the Future national survey results on drug use: 1975-2014: Overview, key findings on adolescent drug use. Ann Arbor: Institute for Social Research, The University of Michigan. Retrieved from http://www.monitoringthefuture.org/pubs/monographs/mtf-overview2014.pdf.

Kelly, A. B., Chan, G. C., Mason, W. A., \& Williams, J. W. (2015). The relationship between psychological distress and adolescent polydrug use. Psychology of Addictive Behaviors, 29(3), 787-793.

Kelly, A. B., Evans-Whipp, T. J., Smith, R., Chan, G. C., Toumbourou, J. W., Patton, G. C., . . . Catalano, R. F. (2015). A longitudinal study of the association of adolescent polydrug use, alcohol use and high school non-completion. Addiction, 110(4), 627635.

King, S. M., Iacono, W. G., \& McGue, M. (2004). Childhood externalizing and internalizing psychopathology in the prediction of early substance use. Addiction, 99(12), 15481559. 
Leatherdale, S. T., \& Ahmed, R. (2010). Alcohol, marijuana, and tobacco use among Canadian youth: Do we need more multi-substance prevention programming? The Journal of Primary Prevention, 31(3), 99-108.

Leatherdale, S. T., Hammond, D., \& Ahmed, R. (2008). Alcohol, marijuana, and tobacco use patterns among youth in Canada. Cancer Causes \& Control, 19(4), 361-369.

Li, Y., Zhang, W., Liu, J., Arbeit, M. R., Schwartz, S. J., Bowers, E. P., \& Lerner, R. M. (2011). The role of school engagement in preventing adolescent delinquency and substance use: A survival analysis. Journal of Adolescence, 34(6), 1181-1192.

Lisdahl, K. M., Gilbart, E. R., Wright, N. E., \& Shollenbarger, S. (2013). Dare to delay? The impacts of adolescent alcohol and marijuana use onset on cognition, brain structure, and function. Frontiers in Psychiatry, 4. doi:10.3389/fpsyt.2013.00053

Marshall, E. J. (2014). Adolescent alcohol use: Risks and consequences. Alcohol and Alcoholism, 49(2), 160-164.

Maslowsky, J., \& Schulenberg, J. E. (2013). Interaction matters: Quantifying Conduct Problem× Depressive Symptoms interaction and its association with adolescent alcohol, cigarette, and marijuana use in a national sample. Development and Psychopathology, 25, 1029-1043.

Matuszka, B., Bácskai, E., Czobor, P., \& Gerevich, J. (2017). Physical aggression and concurrent alcohol and tobacco use among adolescents. International Journal of Mental Health and Addiction, 15, 90-99.

Peters, E. N., Budney, A. J., \& Carroll, K. M. (2012). Clinical correlates of co-occurring cannabis and tobacco use: A systematic review. Addiction, 107(8), 1404-1417.

Reyes, J. C., Perez, C. M., Colón, H. M., Dowell, M. H., \& Cumsille, F. (2013). Prevalence and patterns of polydrug use in Latin America: Analysis of population-based surveys in six countries. Review of European studies, 5(1), 10-18. 
Scheier, L. M., Botvin, G. J., Griffin, K. W., \& Diaz, T. (2000). Dynamic growth models of self-esteem and adolescent alcohol use. The Journal of Early Adolescence, 20(2), 178209.

Shaffer, D., Fisher, P., Lucas, C. P., Dulcan, M. K., \& Schwab-Stone, M. E. (2000). NIMH Diagnostic Interview Schedule for Children Version IV (NIMH DISC-IV): Description, differences from previous versions, and reliability of some common diagnoses. Journal of the American Academy of Child \& Adolescent Psychiatry, 39(1), 28-38.

Shortt, A. L., Hutchinson, D. M., Chapman, R., \& Toumbourou, J. W. (2007). Family, school, peer and individual influences on early adolescent alcohol use: First-year impact of the Resilient Families programme. Drug and Alcohol Review, 26(6), 625634.

Spear, L. (2000). Modeling adolescent development and alcohol. Alcohol Research \& Health, 24(2), 115-123.

Stapinski, L. A., Edwards, A. C., Hickman, M., Araya, R., Teesson, M., Newton, N. C., . . Heron, J. (2016). Drinking to cope: A latent class analysis of coping motives for alcohol use in a large cohort of adolescents. Prevention Science, 17(5), 584-594.

Telethon Kids Institute. (2015). Young Minds Matter: the second Australian Child and Adolescent Survey of Mental Health and Wellbeing, Survey User's Guide. Centre for Child Health Research, University of Western Australia. Retrieved from https://youngmindsmatter.telethonkids.org.au/globalassets/subsite-media/subsitedocuments/young-minds-matter/survey-user-s-guide-final.pdf.

Tomczyk, S., Isensee, B., \& Hanewinkel, R. (2016). Latent classes of polysubstance use among adolescents - A systematic review. Drug and Alcohol Dependence, 160, 12-29. 
Veselska, Z., Geckova, A. M., Orosova, O., Gajdosova, B., van Dijk, J. P., \& Reijneveld, S. A. (2009). Self-esteem and resilience: The connection with risky behavior among adolescents. Addictive Behaviors, 34(3), 287-291.

White, V., \& Williams, T. (2016). Australian secondary school students' use of tobacco, alcohol, and over-the-counter and illicit substances in 2014. Melbourne: Centre for Behavioural Research in Cancer, Cancer Council Victoria. Retrieved from http://www.nationaldrugstrategy.gov.au/internet/drugstrategy/Publishing.nsf/content/ E9E2B337CF94143CCA25804B0005BEAA/\$File/Nationalreport_ASSAD_2014.pdf.

Wiefferink, C. H., Peters, L., Hoekstra, F., Ten Dam, G., Buijs, G. J., \& Paulussen, T. G. (2006). Clustering of health-related behaviors and their determinants: Possible consequences for school health interventions. Prevention Science, 7(2), 127-149.

Wilson, W., Mathew, R., Turkington, T., Hawk, T., Coleman, R. E., \& Provenzale, J. (2000). Brain morphological changes and early marijuana use: A magnetic resonance and positron emission tomography study. Journal of Addictive Diseases, 19(1), 1-22. 
Table 1

Sample profile

\begin{tabular}{|c|c|}
\hline & $\begin{array}{c}\text { Raw } \\
(n=1661)\end{array}$ \\
\hline \multicolumn{2}{|l|}{ Gender (\%) } \\
\hline Male & 50.9 \\
\hline Female & 49.1 \\
\hline \multicolumn{2}{|l|}{ Age (\%) } \\
\hline Mean (SD) & $16.20(0.73)$ \\
\hline 15 years & 18.6 \\
\hline 16 years & 43.2 \\
\hline 17 years & 38.2 \\
\hline \multicolumn{2}{|l|}{ Socioeconomic status quintiles $^{\mathrm{a}}(\%)$} \\
\hline Lowest quintile (most disadvantaged) & 15.6 \\
\hline $2^{\text {nd }}$ & 18.4 \\
\hline $3^{\text {rd }}$ & 18.3 \\
\hline $4^{\text {th }}$ & 23.4 \\
\hline Highest quintile (most advantaged) & 24.5 \\
\hline \multicolumn{2}{|l|}{ Country of birth (\%) } \\
\hline Australia & 85.2 \\
\hline Overseas & 14.8 \\
\hline \multicolumn{2}{|l|}{ Alcohol use (\%) } \\
\hline Yes & 29.4 \\
\hline No & 70.6 \\
\hline \multicolumn{2}{|l|}{ Tobacco use (\%) } \\
\hline Yes & 10.7 \\
\hline No & 89.3 \\
\hline \multicolumn{2}{|l|}{ Cannabis use (\%) } \\
\hline Yes & 7.8 \\
\hline No & 92.2 \\
\hline \multicolumn{2}{|l|}{ Drug use (\%) } \\
\hline 0 substances & 66.9 \\
\hline
\end{tabular}




\begin{tabular}{|l|c|}
\hline 1 substance & 22.1 \\
2 substances & 7.3 \\
3 substances & 3.7 \\
\hline Use patterns (\%) & \\
Alcohol + Tobacco only & 4.2 \\
Alcohol + Cannabis only & 2.3 \\
Tobacco + Cannabis only & 0.8 \\
\hline
\end{tabular}

Note. Missing values treated listwise

${ }^{a}$ The five quintiles each comprise $20 \%$ of areas ranked by socioeconomic status from the most disadvantaged (lowest quintile) to least disadvantaged (highest quintile) (ABS, 2011). 
Table 2

Prevalence of substance use stratified by alcohol, tobacco, and cannabis user status

\begin{tabular}{|c|c|c|c|c|c|}
\hline \multicolumn{2}{|c|}{$\begin{array}{l}\text { Alcohol users } \\
\qquad(n=488)\end{array}$} & \multicolumn{2}{|c|}{$\begin{array}{l}\text { Tobacco users } \\
\qquad(n=178)\end{array}$} & \multicolumn{2}{|c|}{$\begin{array}{l}\text { Cannabis users } \\
\qquad(n=129)\end{array}$} \\
\hline \% using & \% using & \% using & \% using & \% using & \% using \\
\hline tobacco & cannabis & alcohol & cannabis & alcohol & tobacco \\
\hline 27.2 & 20.4 & 73.4 & 40.1 & 77.9 & 56.7 \\
\hline
\end{tabular}


Table 3

Unstandardized and standardized parameter estimates for all variables

\begin{tabular}{|c|c|c|c|c|c|}
\hline & \multicolumn{5}{|c|}{ Poly drug use } \\
\hline IVs & $\mathrm{B}$ & $\beta$ & $S E$ & OR & $90 \% \mathrm{CI}$ \\
\hline \multicolumn{6}{|l|}{ Demographic factors } \\
\hline Gender (1 = male, 2 = female) & 0.06 & .01 & .03 & 1.06 & $0.83,1.34$ \\
\hline Age & 0.75 & .27 & .03 & 2.12 & $1.82,2.47$ \\
\hline SES & 0.01 & .01 & .03 & 1.01 & $0.96,1.05$ \\
\hline $\begin{array}{l}\text { Country of birth (1 = Australia, } \\
2=\text { overseas) }\end{array}$ & -0.60 & -.10 & .04 & 0.55 & $0.38,0.80$ \\
\hline \multicolumn{6}{|l|}{ Psychological factors } \\
\hline Peer problems & -0.10 & -.08 & .04 & 0.91 & $0.83,0.98$ \\
\hline Hyperactivity & 0.06 & .06 & .04 & 1.06 & $1.00,1.12$ \\
\hline Emotional problems & -0.12 & -.13 & .04 & 0.89 & $0.84,0.95$ \\
\hline Conduct problems & 0.30 & .23 & .03 & 1.35 & $1.25,1.45$ \\
\hline Major Depressive Disorder & 0.91 & .13 & .03 & 2.48 & $1.75,3.50$ \\
\hline Self-esteem & -0.02 & -.07 & .05 & 0.98 & $0.96,1.00$ \\
\hline \multicolumn{6}{|l|}{ Environmental factors } \\
\hline Number of friends & 0.16 & .15 & .03 & 1.17 & $1.11,1.24$ \\
\hline Parental monitoring & -0.12 & -.05 & .04 & 0.88 & $0.76,1.03$ \\
\hline Feelings towards school & -0.21 & -.10 & .04 & 0.81 & $0.69,0.94$ \\
\hline School connectedness* & 0.10 & .03 & .05 & 1.10 & $0.87,1.39$ \\
\hline School engagement* & 0.46 & .15 & .04 & 1.58 & $1.26,1.98$ \\
\hline Bullying victim & 0.12 & .06 & .04 & 1.13 & $1.01,1.26$ \\
\hline Social connectedness & 0.49 & .13 & 04 & 1.63 & $1.28,2.07$ \\
\hline
\end{tabular}

Note. Significant results are bolded (at least $p<.05$ )

*Items presented on a scale of 1 (strongly agree) to 5 (strongly disagree), with higher scores indicative of poorer school connectedness and engagement. 
Table 4

Unstandardized and standardized parameter estimates for all variables

\begin{tabular}{|c|c|c|c|c|c|c|c|c|c|c|c|c|c|c|c|}
\hline IVs & \multicolumn{15}{|c|}{ DVs } \\
\hline & \multicolumn{5}{|c|}{ Alcohol use } & \multicolumn{5}{|c|}{ Tobacco use } & \multicolumn{5}{|c|}{ Cannabis use } \\
\hline & B & $\beta$ & $S E$ & OR & $95 \% \mathrm{CI}$ & B & $\beta$ & $S E$ & OR & $95 \%$ CI & B & $\beta$ & $S E$ & OR & $95 \% \mathrm{CI}$ \\
\hline Demographic factors & & & & & & & & & & & & & & & \\
\hline $\begin{array}{l}\text { Gender }(1=\text { male, } 2= \\
\text { female })\end{array}$ & 0.04 & .01 & .04 & 1.04 & $0.82,1.34$ & 0.03 & .01 & .06 & 1.03 & $0.69,1.53$ & -0.55 & -.13 & .07 & 0.58 & $0.36,0.95$ \\
\hline Age & 0.84 & .31 & .03 & 2.31 & $1.97,2.72$ & 0.31 & .11 & .06 & 1.36 & $1.05,1.77$ & 0.29 & .11 & .06 & 1.33 & $1.02,1.75$ \\
\hline SES & 0.01 & .01 & .04 & 1.01 & $0.97,1.06$ & 0.00 & .00 & .05 & 1.00 & $0.94,1.07$ & 0.02 & .03 & .06 & 1.02 & $0.95,1.10$ \\
\hline Country of birth $(1=$ & -0.66 & -.11 & .04 & 0.52 & $0.35,0.76$ & -0.14 & -.02 & .06 & 0.87 & $0.46,1.65$ & -0.81 & -.13 & .07 & 0.45 & $0.22,0.93$ \\
\hline Australia, 2 = overseas) & & & & & & & & & & & & & & & \\
\hline Psychological factors & & & & & & & & & & & & & & & \\
\hline Peer problems & -0.14 & -.12 & .05 & 0.87 & $0.79,0.95$ & 0.00 & .00 & .07 & 1.00 & $0.87,1.15$ & -0.06 & -.05 & .08 & 0.94 & $0.81,1.11$ \\
\hline Hyperactivity & 0.04 & .05 & .04 & 1.05 & $0.98,1.11$ & 0.13 & .14 & .06 & 1.14 & $1.03,1.26$ & 0.04 & .04 & .07 & 1.04 & $0.93,1.16$ \\
\hline Emotional problems & -0.13 & -.15 & .05 & 0.88 & $0.82,0.94$ & -0.13 & -.15 & .07 & 0.88 & $0.79,0.97$ & -0.07 & -.08 & .08 & 0.94 & $0.83,1.05$ \\
\hline
\end{tabular}




\begin{tabular}{|c|c|c|c|c|c|c|c|c|c|c|c|c|c|c|c|}
\hline Conduct problems & 0.27 & .21 & .04 & 1.31 & $1.21,1.42$ & 0.27 & .20 & .05 & 1.30 & $1.18,1.44$ & 0.31 & .24 & .06 & 1.37 & $1.21,1.55$ \\
\hline Major Depressive & 0.78 & .12 & .03 & 2.17 & $1.52,3.09$ & 1.17 & .17 & .04 & 3.24 & $1.94,5.40$ & 0.54 & .08 & .06 & 1.71 & $0.93,3.14$ \\
\hline Self-esteem & -0.03 & -.11 & .05 & 0.97 & $0.95,0.99$ & -0.02 & -.06 & .09 & 0.98 & $0.95,1.02$ & 0.01 & .03 & .08 & 1.01 & $0.98,1.04$ \\
\hline \multicolumn{16}{|l|}{ Environmental factors } \\
\hline Number of friends & 0.15 & .15 & .04 & 1.16 & $1.09,1.24$ & 0.18 & .18 & .06 & 1.20 & $1.09,1.33$ & 0.07 & .07 & .06 & 1.07 & $0.97,1.18$ \\
\hline Parental monitoring & -0.05 & -.02 & .04 & 0.95 & $0.81,1.11$ & -0.11 & -.04 & .05 & 0.90 & $0.71,1.14$ & -0.43 & -.17 & .06 & 0.65 & $0.50,0.84$ \\
\hline Feelings towards school & -0.22 & -.10 & .05 & 0.80 & $0.68,0.95$ & -0.04 & -.02 & .07 & 0.96 & $0.75,0.23$ & -0.19 & -.09 & .08 & 0.83 & $0.64,1.08$ \\
\hline School connectedness* & -0.07 & -.02 & .05 & 0.93 & $0.72,1.20$ & 0.68 & .23 & .08 & 1.97 & $1.32,2.94$ & 0.20 & .07 & .09 & 1.22 & $0.80,1.87$ \\
\hline School engagement* & 0.45 & .15 & .05 & 1.57 & $1.22,2.01$ & 0.34 & .11 & .07 & 1.41 & $0.97,2.04$ & 0.35 & .12 & .08 & 1.42 & $0.97,2.09$ \\
\hline Bullying victim & 0.09 & .04 & .04 & 1.09 & $0.97,1.23$ & 0.03 & .01 & .06 & 1.03 & $0.85,1.25$ & 0.18 & .09 & .05 & 1.19 & $1.01,1.41$ \\
\hline Social connectedness & 0.47 & .13 & .04 & 1.60 & $1.25,2.04$ & 0.33 & .09 & .07 & 1.39 & 0.93, 2.06 & 0.33 & .09 & .08 & 1.39 & $0.89,2.19$ \\
\hline
\end{tabular}

Note. Significant results are bolded (at least $p<.05$ )

*Items presented on a scale of 1 (strongly agree) to 5 (strongly disagree), with higher scores are indicative of poorer school connectedness and engagement. 


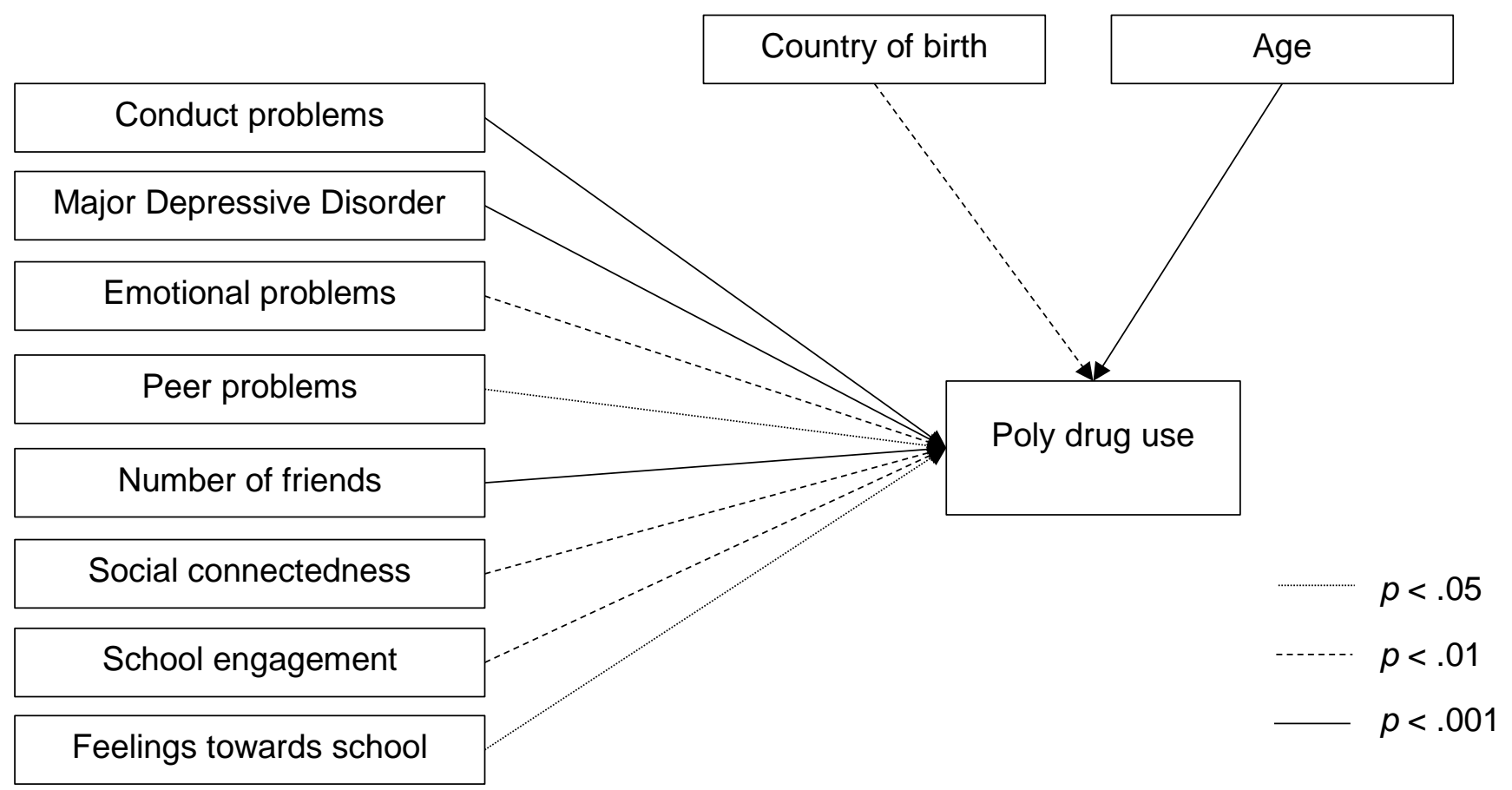

Figure 1. Significant psychological, environmental, and demographic factors associated with poly drug use 


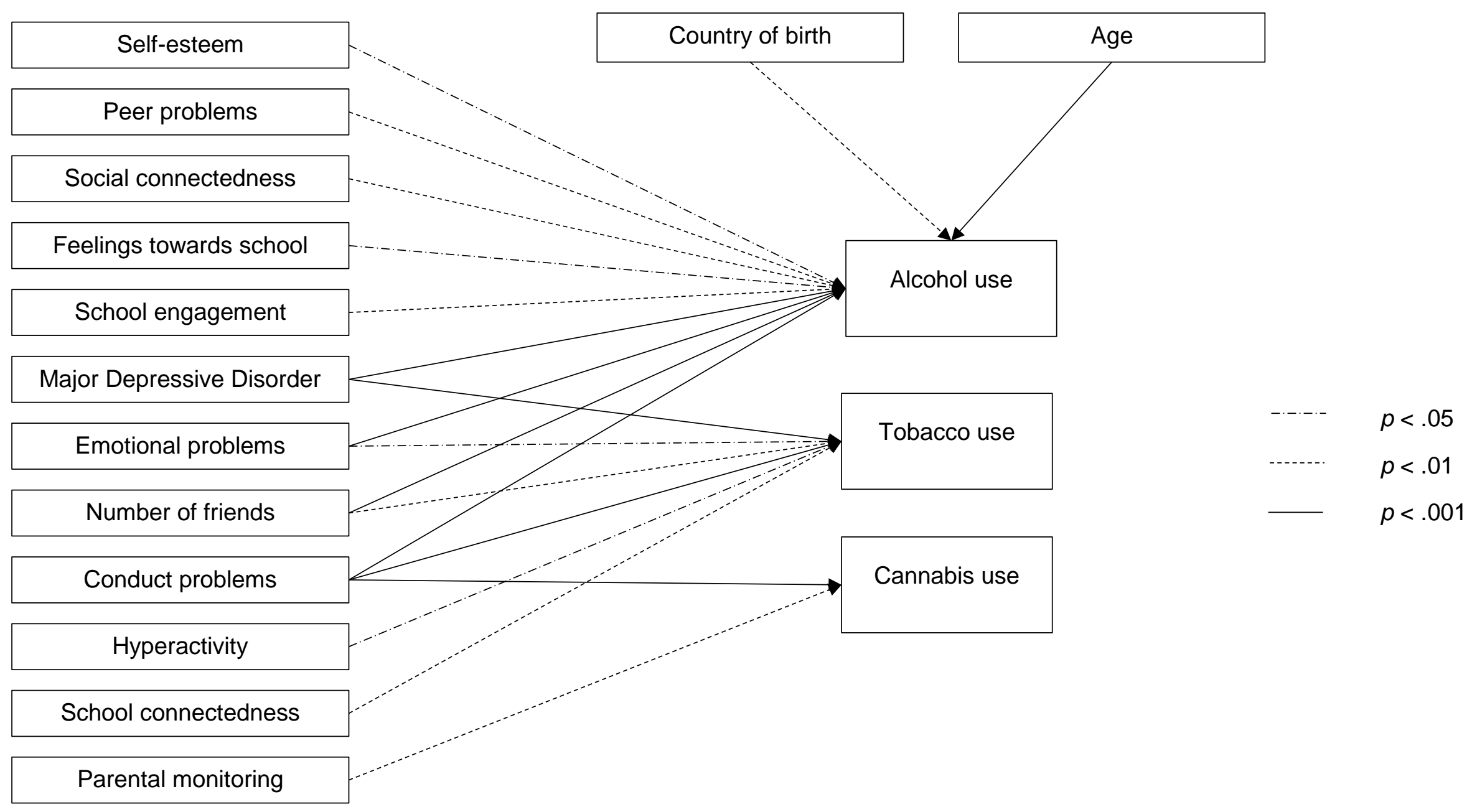

Figure 2. Significant psychological, environmental, and demographic factors associated with alcohol, tobacco, and cannabis use 